\title{
Pseudo Campus: The Future Educational Support
}

\author{
Indiramma, Ph.D \\ BMS College of Engineering, \\ Department of Computer \\ Science, Bangalore.
}

\author{
Abhijith U \\ BMS College of Engineering, \\ Department of Computer \\ Science, Bangalore.
}

\author{
P Anup Nayak \\ BMS College of Engineering, \\ Department of Computer \\ Science, Bangalore.
}

\author{
Pavan N \\ BMS College of Engineering, Department of \\ Computer Science, Bangalore.
}

\section{Sharan R Prasad \\ BMS College of Engineering, Department of Computer Science, Bangalore.}

- To reduce the paper work.

- To automate blended learning system.

\begin{abstract}
The main idea of Blended learning is to overcome some of the disadvantages of traditional classroom interaction of student and instructor. The Blended learning System includes online interactive discussions in addition to the traditional face-toface classroom training. This online environment enables students and instructors to interact as if they were in a real classroom. Through these venues, the instructor can address the questions posed by students immediately. Instructors can integrate this platform in their course design and delivery to ensure that students benefit from a rewarding learning experience. Students can view various posts made by the instructors and also download the resources that are uploaded by them. Students find all the materials relevant to their studies such as syllabus, timetable, lecture videos etc. The students and staff are provided with Login ID and Passwords that help them to get connected to the server. By making use of simple HTML, PHP and MYSQL we achieve this. This contributes for active involvement assessment. Data Mining and Machine Learning algorithms can be applied on the collected data for predictive analysis. Our mission is to make teaching and learning more efficient and enjoyable.
\end{abstract}

\section{Keywords}

User interface, virtual classroom, e-learning, online quiz, webbased applications, face-to-face learning.

\section{INTRODUCTION}

The "Blended Learning" is associated with simply linking traditional classroom training to eLearning activities [23]. The growing popularity of blended-Learning is leading to significant change in educational models. It is a hybrid model, which combines traditional face-to-face teaching with online learning where they need not be present physically in the classroom but connected to the classroom via Internet [11]. It is a design approach where fusion of both face-to-face and online learning is made better by the presence by each other. It is referred to as both hybrid and blended learning, with very little or no difference in the meaning of the two, among most educators.

In general, blended learning combines the best features of classroom interaction and live instruction to personalize learning with online delivery of educational content, allow thoughtful reflection, and differentiate instruction from student to student across a diverse group of learners.

The objectives of the system are -

- To computerize the system.

- To achieve operational efficiency.

- Centralized database management.

- Provides a platform for exchange of thoughts and views on technology.
Teachers can also conduct online quizzes that effectively reduce the time for valuation and are also less prone to errors. Virtual classroom enables to bring learners together online in highly interactive virtual classes. It can be used as a solution for revision and to compensate for missed classes. It facilitates staff and students in teaching-learning events, such as online discussion. It promotes the concept of flipped classroom [5].

We assume that even the offline learning offerings are managed through an online learning system. An example of such blending may include a learning program that will provide research resources and study materials over the web while providing instructor-led, classroom training sessions as the main medium of instruction. Focus is given on providing an overview of Blended learning research.

The features provided by blended learning system:

- Utilizing a part of time by working online from home students can have greater flexibility, freedom and convenience.

- Since it provides numerous opportunities, students are more likely to interact with fellow students and instructors both in class and online.

- Students have unlimited access to various resources available on the platform.

- Students usually receive a feedback from the instructor and in turn the students can rate the instructors.

- Online course materials are available right at fingertips for students $24 * 7$.

- Data Mining Algorithms can be used on the system to predict the students at risk and instructors can guide them to help them succeed by organizing the contents of the site in efficient way [22].

- Students often develop or enhance their skills in time management, problem solving and critical thinking [24].

- Student's and Instructor's quality time is utilized to maximum extent in such a blended learning system.

- The overall effect of these will result in drastic improvement in the student's performance.

\subsection{Concepts of Blended Learning:}

(Integrated with flipped class room)

- Students: [24]

1. Students become a learning community both online and face-to-face.

2. Spend more time working individually and collaboratively on projects and assignments.

- Instructor: [24] 
1. Spend more time reviewing and evaluating student work and guiding and interacting with students.

2. Provide information about topic that is going to be discussed in next class by proving links.

- More opportunities for interaction

- Asynchronous discussion forums

1. Face-to-face discussion

2. Small group work

3. E-mail

4. Online chat

- Instructor can teach in new ways

1. Accomplish new learning goals and objectives.

2. Hands-on student involvement with learning

3. Opportunities to learn in different ways

- Students are held more accountable for own learning

1. Instructors can document \& examine student work more thoroughly online.

2. Brief interactions used to increase participation and communication, to engage learners in the process or content, to enhance content processing and also to give and receive feedback

3. Teacher leads the interactive process but usually fades into the background when learners are interacting

4. Learners discuss ideas or exchange answers and instead of relying on each other for interpretation and guidance tend to look to the teacher for answers.

The layered approach of Blended Learning

Blended learning

Integrating modules with the underlying platform.

Discussion forums that brings entire class to single platform.

Integrating class room learning with online resources.

Traditional face to face learning without online facilities.

Traditional Learning

Figure 1: The layered model of blended learning.

\subsection{Challenges:}

\subsubsection{Course Design Rethinking:}

To teach a successful hybrid course instructors must reexamine their course objectives and goals, design online learning activities to meet these objectives and goals, and effectively integrate the face-to face meetings with the online activities. Instructors must make the transition from presentation and lectures to a more student-centered active learning [24].

\subsubsection{Inculcating New Methods of Teaching:}

The instructors need to learn how to facilitate small group activities and online discussions and re-examine traditional methods of assessment of student work to take the new learning environment into account [24].

\subsubsection{Balancing the Dual Learning Environment:}

The hybrid environment also adds additional scheduling and communication challenges as courses meet both face-to-face and online. Instructors also must take care not to overload themselves and their students [24].

\subsubsection{Preparing Students in This Direction:}

The instructors must be prepared to help students understand their active role in the hybrid, assist students in keeping their work on track, and have to offer strategies for troubleshooting any new course technologies.

\section{SURVEY DETAILS}

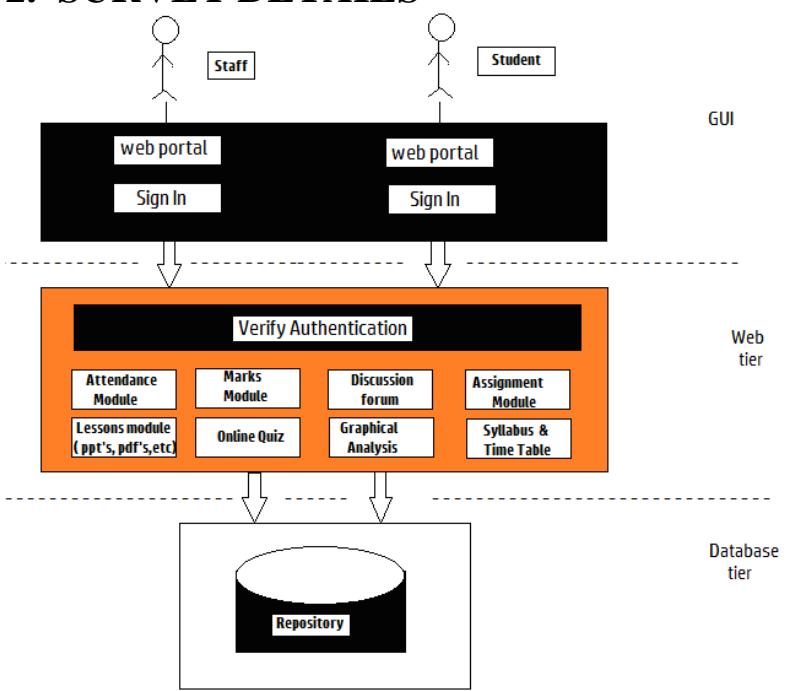

Figure 2: The System architecture of blended learning.

The integrated virtual classroom system consists of a User interface, web portal and a database repository. The client application provides a Graphic User Interface (GUI) to the end users, which is achieved using a web browser, such as Chrome, Firefox, Opera or Internet Explorer. The HTML and CSS with JavaScript is used to build the client-side GUI page [10]. A web server, Apache Server is used to serve the GUI page at the web-tier, and to provide dynamic content HTML/PHP pages. The web-tier holds data models that presents the data models to the client accepts and analyzes through HTML/PHP pages, passes the user's request for authentication and forward response back to the client. A relational database MySQL and PHP are used for server side programming. The database repository should be of a powerful DBMS technology that can handle simultaneous and concurrent transactions [6]. Efficient query writing is also one of the main ingredients in such projects and databases should be perfectly normalized.

The front end is delivered as HTML with CSS and JavaScript to provide eye-catching look and to make it browser independent. The web-portal communicates with the repository through a PHP Interface [6].

A student connects to the application. If the student logs in, the user module maintains student's course registration information. It creates new student records and manages these records. Student records include such information as student ID, name, password, address, phone and email address. 
- User registration module: The application is a HTML form. This includes a student id and password and various types of contact information (email addresses, phone number, and so on). Student information is in the database.

- Assignment module: The application enables students to upload written assignment to course teacher. It also allows course-teacher to grade assignment and publish the result to students.

- Chat module: A chat module is used for live-time discussions. Chat is a very efficient way to discuss things in live-time.

- Attendance module: The application facilitates a flexible way for Instructors to mark attendance online and the same can be used by the students for their reference.

- Lessons module: This feature allows for the addition of lessons that guide the student based on the student's answers. A lesson can be thought of as being similar to a flowchart.

- File/video upload module: The files such as PPT's and PDF's can be uploaded here which serve as a study material to students. Videos too can be shared with the students, which the instructor finds relevant to the topic taught in class.

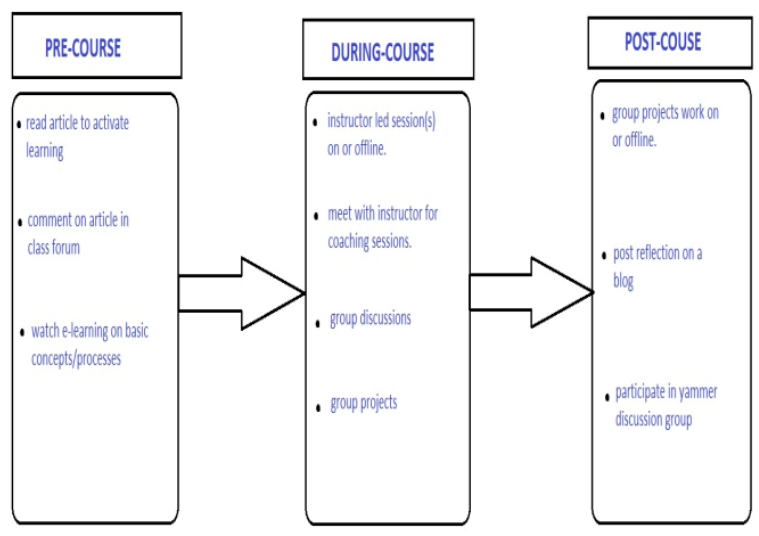

Figure 3: The phases of blended learning [2].

This application models a web-based student course delivery system. The application interface is presented through a hypothetic web site (http://localhost/students) to the students. The student interacts with the application using a web browser. The application presents the student with a catalog of courses. New students are required to register using a username and password pair.

The kinds of functionality, which are available from the user interface of the application, are:

- A common set of navigation bars or links on each page that provide the student with fast access to common navigational tasks.

- A chat facility for student registered for a particular course.

- Access to a forum where users (students and teachers) can exchange ideas on different issues relating to a given course.

- Uploading of assignment and access to submission and also the subsequent access to the graded result.

- Graphical interpretation of the assessments made.

\subsection{Overview of Related Products:}

\subsubsection{HP Virtual Classroom Participant Interface}

2.1.1.1 Features:

- An Attendee List that shows the names of all the attendees.

- Highlighting of one or more names and subsequently using the Private Chat button to start a Private Chat.

- Similarly, Group Chat facilitates sending of messages to all attendees in the classroom.

- Allow the participants to view uploaded files, URL's and other contents in a separate pop-up window.

\subsubsection{Comments:}

- $\quad$ Print and Save Feature of this virtual classroom is useful. Using this data a session can be saved or printed for future use.

- Usage of this virtual classroom, requires it has to be purchased. It is not available free of cost.

- Completely an online virtual classroom.

- Importance towards face to face learning is not considered

\subsubsection{IBM Virtual Classroom Participant \\ Interface}

2.1.2.1 Features: [21]

- IBM Lotus virtual classroom provides support to real time Audio as well as Video.

- Virtual classroom sessions can be recorded. The sessions can then be bare played as if they are videos. Instructors or learners can replay the sessions at any time once the session has finished.

- The Outline function allows the teacher to define the agenda of the virtual classroom session. The outlines are usually defined before the start of a meeting.

- The presenter can send Web pages to class participants. Resulting in an opening of a new browser window on each person's machine. Participants can then independently view the Web page and navigate through it.

- Breakout sessions allows presenter to divide the participants into groups to discuss a specific topic or to work on a group assignment .After participants have entered the breakout session, it portrays as if they are in a different room.

\subsubsection{Comments:}

- IBM virtual classroom has several useful features such as outline, screen-sharing, breakout rooms that add greater interactivity between presenter and participants

- No predictive analysis techniques which helps in improvement of student's performance.

2.1.3 Wiksate

2.1.3.1 Features:

- Instructors can easily create learning and share the lecture notes and presentations.

- Even the students themselves can create the learning's and share them.

- There is a dashboard provided that gives the status of each user's involvement on the website. 


\subsubsection{Comments:}

- This website proves the thinking for blended learning where the students can revise the learning's in the evenings at home.

- This website does not provide any features where the student gets to know the internal assessment marks as well as the attendance status.

- This website also does not provide the features such as online quiz.

\section{BENEFITS/SOCIAL OUTCOME.}

- Increase participation.

- Decrease student isolation.

- Support quick and easy communication, and support the usage of interactive instructional strategies.

- A popular use of discussion forums is to set up a $\mathrm{Q}$ \& A forum where students are encouraged to answer each other's questions. The instructor then will monitor the discussion and will step in if something needs clarification or if students are unable to answer the question. Having such a forum in place can help students prepare for classes, as students will be aware of the areas where they are having trouble.

- Another use of discussion forums is to have students discuss topics that were brought up in class. This allows students to actively participate in learning as they continue conversations and ask questions.

- There is both time drain and an expense associated with paper copies. There is a need to reduce the paper consumption. Teachers can upload the course materials such as lecture notes, PDF's, presentation slides and videos which are valuable assets to the students.

- Also the accuracy of the automatic valuation of MCQ's by the system will be less error prone than manual valuation.

- Providing quizzes and tests online allows you more time for discussion and activities in the classroom. You can present questions/problems that require an understanding of the material in an online test or quiz. Test questions or objective quiz can be loaded into a question pool that allows each student to get a different quiz or test. This allows students a place to share ideas as they work on their projects and eliminates some time/place meeting constraints.

- Able to post the grade and feedback for the student. Students can get their feedback and grade on their website home page.

- Students will come to class expecting a revised course structures and methods that incorporate the use of Blended learning component.

\section{CONCLUSION \& FUTURE WORK}

Blended learning is more than just electronic textbooks and interactive tools. Moreover it is inventing or adopting new learning environments that work better for student and staff. Blended learning implies a shift to an online environment for a portion of the student's day. It provides students more control over not only the pace, path but also time and place of learning.

Implementation of blended learning is about bringing to life fundamental shifts in teaching and learning. The goal is to personalize learning using modern technology and expand learning opportunities in the context of common core and other emerging standards and technology requirements.

Blended learning is in its early stage and there is a need to explore it and access its transformative potential. Over the coming years this research will facilitate the development and implementation of blended learning offering students everywhere the promise of better education.

We conclude this document by providing several examples and ideas for further research, such as audio and video chats that further enhances the blended classroom experience.

With the amount of data being stored into the database we can apply the Machine Learning and Data Mining techniques such as Naïve Bayesian or Decision trees algorithms to predict the student at risk of underperformance. If prediction about the performance of students can be done beforehand then we can have an insight into the area to improve upon [22].

With advancements happening in Data Mining area the current trend suggest that the platform will become a potential hotspot in near future and if it can be extract into the educational structure will help in realization of the true potential of education system.

This feature can be extended to an android Application. This facilitates the users to access the same features through their smart phones. These functionalities can be considered as a further work to be done for our classroom.

\section{ACKNOWLEDGEMENT}

The authors would like to acknowledge and thank Technical Education Quality Improvement Programme [TEQIP] phase2, and BMS College of Engineering, Bangalore for supporting the research work.

\section{REFERENCES}

[1] Renate Motschnig-Pitrik and Katharina Mallich "Effects of Person-Centered Attitudes on Professional and Social Competence in a Blended Learning Paradigm", Educational Technology \& Society, 7 (2004), 176-192.

[2] Jeff Pankin, John Roberts, Mike Savio, "Blended Learning at MIT”, white paper, July 2012

[3] Elizabeth Stacey\&Philippa Gerbic, "Success factors for blended learning", Proceedings ascilite Melbourne 2008.

[4] Farhod P. Karimov, Malaika Brengman\&Leo Van Hove, "The effect of website design dimensions on initial trust:a synthesis of the empirical literature", Journal of Electronic Commerce Research, VOL 12, NO 4, 2011.

[5] Noora Hamdan and Patrick McKnight,et. al., "A review of Flipped learning", white paper,2007.

[6] The Architectural Design of an Integrated Virtual Classroom SystemDepartment of Mathematics, Statistics and Computer Science,Kaduna Polytechnic, Kaduna, Nigeria

[7] Hiltz, S.R., 1994. The Virtual Classroom: Learning Without Limits Via Computer Networks. Ablex Publishing Corporation, Norwood, NJ.

[8] Mbing Isaac ,A.I. Obasa and A.A. Eludire, "The Architectural Design of an Integrated Virtual Classroom System", Research Journal of Information Technology 3(1): 43-48, 2011,ISSN: 2041-3114.

[9] Radu Dondera, Chun Jia, Voicu Popescu,Cristina NitaRotaru, Melissa Dark, and Cynthia York, "Virtual 
Classroom Extension for Effective Distance Education", Purdue University,2005.

[10] Nattha Buasri, Tanasak, Yamboristu, and Wongsawang, "Web-based interactive virtual classroom using HTML5based technology", Student Project Conference (ICTISPC), 2014 Third ICT International, 978-1-4799-5572-5

[11] Chin-Yi Yang, Ching-Tao Chang, Li-Ren Chien, "A Teacher Control Model of a Blended Learning Environment based on a Typical Classroom in Secondary School", 2010,IEEE, 2nd International Conference on Computer Engineering and Technology, 978-1-4244$6349-7 / 10 / \$ 26.00$

[12] Sepehr Ghassemi, Fattaneh Taghiyareh,Fateme Orooji,"Developing A Learner-Centered Criteria to Assessing Group Activities in Blended Learning Environments", 978-1-4673-6490-4/13,2013,IEEE.

[13] S. Djenic, R. Krneta, and J. Mitic; "Blended Learning of Programming in the Internet Age", IEEE TRANSACTIONS ON EDUCATION, VOL. 54, NO. 2, MAY 2011.

[14] C. J. Bonk and C. R. Graham, The Handbook of Blended Learning: Global Perspectives, Local Designs. San Francisco, CA: Pfeiffer, 2006.

[15] S. Hadjerrouit, "Towards a blended learning model for teaching and learning computer programming: A case study,"nform. Educ., vol. 7, no. 2, pp. 181-210, 2008.

[16] Ashish Amresh, Adam R. Carberry and John Femiani, "Evaluating the Effectiveness of Flipped Classrooms for Teaching CS1", 978-1-4673-5261-1/13/\$31.00,2013
IEEE.

[17] Ryan McFall, Mark Urban-Lurain and Weinshank, "A WEB-TO-DATABASE SYSTEM FOR COLLECTING STUDENT DATA", 0-7803-7444-4/02/.\$17.00 02002 IEEE.

[18] Thomas G. Cleaver and Robert L. Toale, "Design of a Web-Based Education Environment", 0-7803-5643 8/99/\$10.00, 1999 IEEE.

[19] Zhang Yi, Mo Xiao-hui, "Research on Virtual Cla ssroom Based on CSCL", 978-0-7695-3982-9/10 \$26.00, 2010 IEEE.

[20] Yi-Wen Luo, "The Effect of Using JavaScript and HTML to Implement an E-learning Web Sites as a Remedial Teaching Aid on English Underachievers at Universities of Science and Technology", Department of Information Management, Chung Hwa University of Medical Technology.

[21] Using IBM Lotus Virtual Classroom: A Best Practices Guide to e-Learning. International Technical Support Organization, IBM, Feb 2003.

[22] Performance Prediction of Engineering Students using Decision Trees, RR Kabra \& RS Bichkar, IJCA, December 2011.

[23] A white Paper: Achieving Success with Blended Learning by Harvi Singh and Chris Reed, Centra Software.

[24] http://www4.uwm.edu/ltc/hybrid/student_resources/?prin tformat=TRUE 